\title{
Trafik İşaretlerinin Bilinirliği Üzerine Bir Araştırma: Denizli Örneği
}

\author{
Yetiş Şazi MURAT ${ }^{1}$, Ziya ÇAKICI ${ }^{2 *}$ \\ ${ }^{1}$ Pamukkale Üniversitesi, Inşaat Mühendisliği Bölümü, Denizli \\ ${ }^{2}$ Pamukkale Üniversitesi, Fen Bilimleri Enstitüsü, Denizli
}

\begin{abstract}
Özet
Ülkemizde, her yll yüksek düzeyde maddi ve manevi kayıplara yol açan en önemli unsurlardan birisi de trafik kazalarıdır. Yaya ve sürücülerin hatalı davranışları, yönlendirici trafik işaret ve levhalarının yetersizliği ve ayrıca trafik işaret ve levhalarının hem sürücüler hem de yayalar tarafından yanlış algılanması trafik kazalarının sayısını arttıran başlıca etmenlerdir. Bu yüzden, trafik işaret ve levhalarının sürücüler ve yayalar tarafından doğru algılanması, trafik güvenliğinin tam anlamıyla sağlanması açısından önemli bir adım olarak görülmektedir.

Bu çalışma, Ege bölgesinin en büyük şehirlerinden birisi olan Denizli' deki sürücülerin, trafik işaretleri ve levhaları hakkındaki bilgi ve farkındalık düzeylerinin yeterli olup olmadığını belirlemek amacıyla yapılmıştır. Çalışma kapsamında, öncelikli olarak, günlük hayatta sıkça karşılaşılan 27 adet trafik işaret ve levhası seçilerek çoktan seçmeli 27 soruyu içeren bir anket oluşturulmuştur. Bir sonraki aşamada ise, bir önceki aşamada oluş̧urulan anketler, sürücü belgesine sahip 500 kişiye dağıtılmış ve bu kişilerin anketteki soruları cevaplamaları istenmiştir. Daha sonra, katılımcılardan toplanan anketler, MS Excel ortamında, soru bazlı değerlendirilmiştir. Değerlendirmeler, 5 farklı bilinirlik düzeyi göz önünde bulundurularak gerçekleştirilmiş̧tir.

Elde edilen sonuçlara göre, ankette yer alan trafik işaretlerinin yaklaşık \% 40 ' nın orta, düşük veya çok düşük bilinirlik düzeyine sahip olduğu görülmüştür. Ayrıca, bu işaretlerin yalnızca $\% 25$ ' inin çok yüksek bilinirlik düzeyine sahip olduğu belirlenmiş̧tir. Bu bilgiler ışığında, genel olarak, sürücülerdeki bilgi ve farkındalığın yeterli düzeyde olmadığı söylenebilir. Bununla birlikte, ilerleyen süreçte, farklı yöntemler (simülasyonlar, oyunlar vb.) kullanılarak, trafikte bilgi ve farkındalık düzeyinin önemli oranda arttırılabileceği düşünülmektedir.
\end{abstract}

Anahtar kelimeler: Trafik, Trafik İşaretleri, Trafik Güvenliği, Anket.

\section{An Investigation on the Awareness of Traffic Signs: Denizli Sample}

\begin{abstract}
In Turkey, one of the most important factors which causes high-level material and spiritual losses in every year is also traffic accidents. Faulty behaviours of the pedestrians and drivers, deficiency of traffic signs and also misperception of traffic signs by both drivers and pedestrians are the main factors increasing the number of traffic accidents. Therefore, the right perception of traffic signs by drivers and pedestrians is considered as an important step in terms of literally ensuring of traffic safety.

This study is conducted in order to determine whether the knowledge and awareness level about traffic signs of drivers who are in Denizli where is one of the biggest cities of Aegean Region in Turkey is sufficient or not. In the scope of the study, firstly, 27 traffic signs which are frequently encountered by drivers in daily life are selected and a questionnaire containing multiple-choice questions is created. In the next step, the questionnaires which are created in previous step are offered to 500 people having driver licence and it is wanted that these 500 people answer the questions in the questionnaire. Then, questionnaires collected from participants are evaluated on question-based in MS Excel environment. The evaluations are realized considering 5 different awareness levels. According to the obtained results, it has been seen that $40 \%$ of traffic signs in questionnaire have medium, low or very low awareness levels. Besides, it has been determined that only $25 \%$ of these signs have very high awareness level. In the light of these information, in general, it can be said that drivers have not sufficient and satisfactory awareness levels on traffic signs. However, it has been thought that the level of knowledge and awareness on traffic can be increased significantly by using different methods such as simulations, games and etc. in the future.
\end{abstract}

Keywords: Traffic, Traffic Signs, Traffic Safety, Questionnaire. 


\section{Giriş}

Özellikle son yıllarda, dünya nüfusundaki sürekli artışa paralel olarak, gelişen ve gelişmekte olan birçok ülkede motorlu taşıt sayısı da önemli düzeyde artış göstermektedir. Bu durum, günlük hayatı birçok yönden kolaylaştırmasına rağmen, çeşitli problemleri de beraberinde getirmektedir. Yüksek trafik yoğunluğundan kaynaklanan egzoz emisyonu, yakıt tüketimi ve gürültü kirliliği artışı, karayolunun kritik kesimleri olan kavşaklarda meydana gelen trafik tıkanıklıkları ve karayollarının farklı kesimlerinde gözlemlenebilen trafik kazaları söz konusu problemlerden yalnızca birkaçıdır [1]. Genel itibari ile bakıldığında, maddi ve manevi kayıplara yol açmasından dolayı, trafik kazaları bu problemlerin en önemlisi olarak değerlendirilebilir [2, 3]. Ülkemizde de karayollarında gerçekleşen trafik kazası sayısının yıldan yıla artışı, bu sayının azaltılması için, Karayolları Genel Müdürlügü, belediyelere ait ulaşım birimleri vb. tarafından çeşitli önlemlerin alınması gerekliliğini açıkça ortaya koymaktadır. Bu bağlamda, karayollarındaki trafiğin güvenli ve düzenli bir şekilde akışını sağlamak için, geometrik düzenlemeler, sinyalizasyon uygulamaları ve trafik işaretleri ile yönlendirme gibi farklı yöntemlere başvurulmaktadır. Karayollarındaki geometrik düzenlemeler trafik mühendisleri ve ulaşım plancıları gibi karar vericiler tarafından gerçekleştirilmektedir. Genel olarak, yapılan düzenlemelerin mantıklı ve standartlara uygun olması durumunda, yol kullanıcıları yoldaki geometrik düzenlemelere kolay bir şekilde uyum sağlamakla birlikte seyahatlerini de güvenli bir şekilde devam ettirebilmektedirler. Sinyalizasyon uygulamaları da, karayollarının kritik kesimleri olan kavşaklarda, trafik güvenliğini arttırmak ve trafiğgin daha düzenli akışını sağlamak için yaygın olarak kullanılan yöntemlerdendir [4]. Geometrik düzenlemeler ve sinyalizasyon uygulamalarının yanı sıra, trafikte yayaları ve sürücüleri doğru bir şekilde yönlendirerek, trafiğin güvenli ve düzenli bir şekilde akışını sağlayan bir diğer önemli faktör de trafik işaretleridir [5]. Ülkemizde, trafik işaretleri; Tehlike Uyarı İşaretleri, Trafik Tanzim İşaretleri, Bilgi İşaretleri, Durma ve Park etme İşaretleri ve Yatay İşaretlemeler olmak üzere 5' e ayrılmaktadır ve kısaca şu şekilde açılanabilmektedir:

- Tehlike Uyarı İşaretleri: Sürücüleri yolun tehlikeleri konusunda uyarmak amaciyla oluşturulmuş olan işaretlerdir.

- Trafik Tanzim İşaretleri: Genellikle özel durumları içermekle birlikte, trafiğin akışını düzenlemeye yönelik oluşturulmuş işaretlerdir.

- Bilgi İşaretleri: Yol güzergahı ve çevresi hakkında yolu kullananlara çeşitli bilgiler sağlamak amaciyla oluşturulmuş işaretlerdir.

- Durma ve Park etme İşaretleri: Sürücülerin araçlarını park edebilecekleri ya da durdurabilecekleri yerlerin denetimi ve düzenlenmesi için oluşturulmuş işaretlerdir.

- Yatay İşaretlemeler: Trafiğin düzenlenmesi, bazı yasaklama ve kısıtlamaların belirtilmesi ve yolu kullananlara rehberlik etmesi amacı ile yol yüzeyine çizilen çizgiler, oklar ve yazılan semboller, yazilardır.

Açıklamalardan da anlaşılabileceği üzere, trafik işaretleri trafiğin düzenli ve güvenli bir şekilde akışını sağlamak için, karayollarının ilgili kesimlerinde kesinlikle bulunmaları gereken önemli elemanlardır. İşaretlemelerin yeterli, standartlara uygun ve yerinde yapılmasının yanı sıra, anlamlarının da yol kullanıcıları tarafından yeterince bilinir ve kavranır olmasının trafiğgin güvenli ve düzenli akışının sağlanması açısından oldukça önemli olduğu unutulmamalıdır. Örneğin, "Kaygan Yol" işaretinin bulunduğu bir karayolu kesiminde, seyir halinde olan bir sürücü, bu işaretin anlamını bildiği takdirde gerekli önlemleri alıp (hız yavaşlatma vb.) hareketini güvenli bir şekilde devam ettirebilmektedir. Fakat sürücü, bu işaretin anlamını bilmediği takdirde ise herhangi bir önlem almadığı için, platformdan çıkma vb. gibi olumsuz durumlarla karşı karşıya kalabilmektedir.

Tablo 1' den de görüldüğ̈̈ üzere, ülkemizde trafik kazalarının büyük bir çoğunluğunun sürücü kaynaklı olduğu bilinmektedir [6,7]. Bu yüzden, trafikte bilgi, algılama ve farkındalık kavramlarının, trafik güvenliğinin tam anlamıyla sağlanması bağlamında oldukça önemli olduğu açıkça görülmektedir.

Tablo 1. Ülkemizde trafik kazalarına neden olan kusurlar

\begin{tabular}{|c|c|c|c|c|c|}
\hline Yıllar & $\begin{array}{c}\text { Sürücü Kusuru } \\
(\boldsymbol{\%})\end{array}$ & $\begin{array}{c}\text { Yolcu Kusuru } \\
(\boldsymbol{\%})\end{array}$ & $\begin{array}{c}\text { Yaya Kusuru } \\
(\boldsymbol{\%})\end{array}$ & $\begin{array}{c}\text { Yol Kusuru } \\
(\boldsymbol{\%})\end{array}$ & $\begin{array}{c}\text { Araç Kusuru } \\
(\boldsymbol{\%})\end{array}$ \\
\hline $\mathbf{2 0 0 2}$ & 96.82 & 0.23 & 2.39 & 0.25 & 0.31 \\
\hline $\mathbf{2 0 0 3}$ & 97.03 & 0.16 & 2.32 & 0.22 & 0.27 \\
\hline
\end{tabular}




\begin{tabular}{|l|l|l|l|l|l|}
\hline $\mathbf{2 0 0 4}$ & 97.30 & 0.11 & 2.18 & 0.19 & 0.22 \\
\hline $\mathbf{2 0 0 5}$ & 97.39 & 0.11 & 2.04 & 0.22 & 0.25 \\
\hline $\mathbf{2 0 0 6}$ & 98.07 & 0.09 & 1.62 & 0.13 & 0.10 \\
\hline $\mathbf{2 0 0 7}$ & 98.03 & 0.09 & 1.64 & 0.11 & 0.14 \\
\hline $\mathbf{2 0 0 8}$ & 90.53 & 0.43 & 8.37 & 0.42 & 0.26 \\
\hline $\mathbf{2 0 0 9}$ & 89.60 & 0.41 & 9.09 & 0.61 & 0.29 \\
\hline $\mathbf{2 0 1 0}$ & 89.72 & 0.39 & 9.86 & 0.69 & 0.36 \\
\hline $\mathbf{2 0 1 1}$ & 90.20 & 0.39 & 8.51 & 0.60 & 0.30 \\
\hline $\mathbf{2 0 1 2}$ & 88.86 & 0.44 & 9.75 & 0.62 & 0.33 \\
\hline $\mathbf{2 0 1 3}$ & 88.69 & 0.42 & 8.99 & 1.05 & 0.85 \\
\hline $\mathbf{2 0 1 4}$ & 88.62 & 0.47 & 9.38 & 0.95 & 0.58 \\
\hline $\mathbf{2 0 1 5}$ & 89.30 & 0.43 & 8.80 & 0.91 & 0.55 \\
\hline Veriler TÜIK web sayfasından alınmıştır. & & & \\
\hline
\end{tabular}

Literatürde, yol kullanıcıları ile ilişkili olan bu kavramlara dayalı yapılan çalışma sayısı da bir hayli fazladır. Bu çalışmalardan bazıları şu şekilde özetlenebilir: Al-Madani ve Al-Janahi, sürücülerin yaşlarının, medeni hallerinin, cinsiyetlerinin, eğitim geçmişlerinin ve aylık gelirlerinin, trafik işaretlerinin bilinirliği üzerindeki etkilerini araştırmışlardır. Çalışma sonucunda yaş, cinsiyet, eğitim ve gelir faktörlerinin trafik işaretlerinin bilinirliğinde önemli bir role sahip olduğu belirlenmiştir. Medeni hal etmeni ise trafik işaretlerinin bilinirlik düzeyi ile ilişkilendirilememiştir. Çalışma kapsamında ayrıca, Avrupa ve Amerika' daki sürücülerin trafik işaretlerine hâkimiyet düzeyinin, Asya ve Arabistan' daki sürücülerden çok daha fazla olduğu sonucuna ulaşılmıştır [8]. Shınar ve diğ., yapmış oldukları çalışmada, sürücüleri beş farklı gruba ayırarak, farklı ülkelerde kullanılan karayolu trafik işareti sembollerinin bilinirlik düzeylerini değerlendirmişlerdir. Çalışma sonucunda, sürücü gruplarının ve ülkelerin, trafik işaretlerinin bilinirliğinde önemli düzeyde farkl1lıklar gösterdiği görülmüştür [9]. W. Y. $\mathrm{Ng}$ ve H. S. Chan, farklı trafik deneyimlerinin trafik işaretleri hakkında bilgi veya farkındalık düzeyini arttırmadığını belirtmişlerdir. Çalışma sonucunda, bir trafik işaretinin bilinirliğinin sırasıyla anlamsal yakınlık, aşinalık, anlamlılık, somutluk, basitlik faktörleri ile doğrudan ilişkili olduğu belirlenmiştir. Buna ilave olarak, kullanıcı dostu ve kolay algılanabilir trafik işaretleri tasarlamak için, tasarımcılara tasarım aşamasında, bu beş faktörü kesinlikle göz önünde bulundurmaları önerilmiştir [10]. Yine W. Y. $\mathrm{Ng}$ ve H. S. Chan, trafik işaretlerinin bilinirliğinde, işaret tasarım özellikleri ve sürücü faktörlerinin etkileri üzerinde çalışmışlardır. Çalışma sonucunda, eğitim düzeyi ve deneyimin (ehliyete sahip olarak geçirilen yıl) trafik işareti bilinirliğinde oldukça etkin faktörler olduğu sonucuna ulaşılmıştır. Bunun yanı sıra, yaş, aktif sürüş yılı, sürüş saati ve sürüş frekansının ise bilinirlik üzerinde önemli bir etkiye sahip olmadığı belirtilmiştir [11]. Tüydeş Yaman ve Kırmızıoğlu, Türkiye' deki sürücüler arasında trafik işaretlerinin anlaşılabilirliği üzerine bir çalışma yapmışlardır. Çalışma kapsamında, Ankara' daki 1478 sürücüye, günlük hayatta sıkça karşılaşılan 30 farklı trafik işaretini içeren bir anket uygulanmıştır. Çalışma sonucunda, bilinirlik düzeyi yetersiz olan trafik işaretlerinin bilinirlik düzeyini arttırmak için daha fazla ve daha atılgan çalışmalar yapılması gerektiği vurgulanmıştır [12]. Özen ve diğ., Uşak ili genelinde yapmış oldukları çalışmada, bireylerin, trafik kuralları ve trafikle ilgili yetkili birimler hakkında yetersiz bilgiye sahip olduklarını ve bunun yanı sıra trafik eğitimi konusunda da daha fazla çalışmalar yapılması gerektiğini belirtmişlerdir [13]. Ben-Bassat ve Shinar, trafik işaretlerinin bilinirliğinin sürücülerin yaşları ile bağlantılı olup olmadığını araştırmışlardır. Çalışma sonucunda, trafik işaretlerinin bilinirliği ve kavranması durumları dikkate alındığında, hem doğruluk hem de tepki süresi açısından genç sürücülerin yaşlı sürücülere oranla daha iyi bir performans gösterdiği belirlenmiştir [14]. Trifunovic ve diğ., biraz daha farklı bir konuya değinerek, çocukların trafik güvenliği için, mekânsal yönlendirmenin ve trafik işaretlerinin bilinirliğinin önemi üzerinde çalışmışlardır. Çalışmada, çocuklara küçük yaşlardan itibaren yeterli ve kaliteli trafik eğitiminin verilmesi gerekliliği üzerinde durulmuştur. Ayrıca, kaliteli ve uygun trafik eğitiminin oyun yöntemiyle daha kolay gerçekleştirilebileceğinden bahsedilmiştir [15]. 
Daha önce yapılan çalışmalardan da görüldügü üzere, hem insan ile ilgili faktörler (yaş, cinsiyet, eğitim düzeyi vb.) hem de bölge farklılığ faktörü trafik işaretlerinin bilinirliği üzerinde oldukça etkilidir. $\mathrm{Bu}$ çalışmada da, trafik işaretlerinin bilinirliği, anket yöntemi ile Denizli kent merkezi ölçeğinde değerlendirilmiştir. Çalışmanın bir sonraki bölümde, anket içeriğinden ve ankette yer alan trafik işaretlerinden detaylı olarak bahsedilirken, üçüncü bölümde anket sonuçları ile ilgili istatistiksel bilgiler verilerek elde edilen bulgulara değinilmiştir. Çalışmanın son bölümünde ise elde edilen bulgular değerlendirilmiş ve yorumlanmıştır.

\section{Materyal ve Metot}

Denizli'deki sürücülerin günlük hayatta sıcça karşılaşılan trafik işaretleri ile ilgili bilgi düzeylerini ölçmek için hazırlanan anket, 27 adet trafik işaretinden oluşmaktadır. Bu işaretlerin 13' ü Tehlike Uyarı İşaretleri, 8' i Trafik Tanzim İşaretleri, 4' ü Bilgi İşaretleri ve 2' si de Durma ve Park etme İşaretleri kapsamındadır.

Katılımcılara sorulan söz konusu işaretler trafik mühendisliği alanında deneyimli iki akademisyen tarafindan belirlenmiştir. Bu aşamada, sürücülerin günlük hayatta sıkça karşılaştığı ve bilinme düzeyinin yüksek olması gerektiği düşünülen trafik işaretlerinin seçilmesine dikkat edilmeye çalışılmıştır. Bunun yanı sıra, trafik işaret sembolünden, trafik işareti anlamının direkt olarak çıkarılamayacağı işaretlerin seçilmesine özen gösterilmiştir. Kısacası, sürücülerin sıkça karşılaştığı fakat yapı itibariyle sürücülerde biçimsel (sembolik) olarak kolay bir şekilde farkındalık oluşturmayan işaretlerin seçimine ağırlık verilmiştir. Böylece, sürücülerin bu işaretler ile ilgili bilgi ve farkındalık düzeylerinin ölçülmesi hedeflenmiş̧ir.

Ankette katılımcılara çoktan seçmeli olarak sorulan Tehlike Uyarı İşaretleri Tablo 2' de detaylı olarak sunulmaktadır.

Tablo 2. Ankette katılımcılara sorulan tehlike uyarı işaretleri

\begin{tabular}{|c|c|c|c|c|c|}
\hline No & $\begin{array}{l}\text { Trafik İşareti } \\
\text { Gösterimi }\end{array}$ & $\begin{array}{l}\text { Kullanıcılara Sunulan } \\
\text { Cevap Seçenekleri }\end{array}$ & No & $\begin{array}{l}\text { Trafik İşareti } \\
\text { Gösterimi }\end{array}$ & $\begin{array}{l}\text { Kullanıcılara Sunulan } \\
\text { Cevap Seçenekleri }\end{array}$ \\
\hline 1 & & $\begin{array}{l}\text { a) İleriden sağa mecburi yön } \\
\text { b) Sağdan daralan kaplama } \\
\text { c) Sağa tehlikeli viraj } \\
\text { d) Sağdan anayola giriş } \\
\text { e) Sağa tehlikeli devamlı virajlar }\end{array}$ & 2 & & $\begin{array}{l}\text { a) Duraklamak ve park etmek } \\
\text { yasaktır } \\
\text { b) Taşıt trafiğine kapalı yol } \\
\text { c) Kontrolsüz demiryolu geçidi } \\
\text { d) Ana yol - tali yol kavşağı } \\
\text { e) Kontrolsüz kavşak }\end{array}$ \\
\hline 3 & & $\begin{array}{l}\text { a) Sola tehlikeli devamlı } \\
\text { virajlar } \\
\text { b) Sola tehlikeli viraj } \\
\text { c) Soldan anayola giriş } \\
\text { d) Ileri ve sola mecburi yön } \\
\text { e) Tehlikeli viraj yön levhası }\end{array}$ & 4 & & $\begin{array}{l}\text { a) Ana yol - tali yol kavşağı } \\
\text { b) Kontrollü demiryolu geçidi } \\
\text { c) Soldan daralan kaplama } \\
\text { d) Sağdan ve soldan anayoldan } \\
\text { çıkış } \\
\text { e) Kontrolsüz kavşak }\end{array}$ \\
\hline 5 & & $\begin{array}{l}\text { a) Engel } \\
\text { b) Deniz veya nehir kıyısında } \\
\text { biten yol } \\
\text { c) Gevşsek şev } \\
\text { d) Tehlikeli eğim (iniş) } \\
\text { e) Tehlikeli eğim (çıkış) }\end{array}$ & 6 & & $\begin{array}{l}\text { a) Kontrolsüz demiryolu geçidi } \\
\text { b) Kontrollü demiryolu geçidi } \\
\text { c) Düşük banket } \\
\text { d) Onarım yaklaşım levhası } \\
\text { e) Kontrolsüz demiryolu geçidi } \\
\text { (tek hat) }\end{array}$ \\
\hline 7 & & $\begin{array}{l}\text { a) Önceliği olan yol } \\
\text { b) İleri mecburi yön } \\
\text { c) Soldan daralan kaplama } \\
\text { d) Her iki taraftan daralan } \\
\text { kaplama } \\
\text { e) Sağdan daralan kaplama }\end{array}$ & 8 & & $\begin{array}{l}\text { a) Sola tehlikeli viraj } \\
\text { b) Sola tehlikeli devamlı virajlar } \\
\text { c) Soldan daralan kaplama } \\
\text { d) Tehlikeli viraj yön levhası } \\
\text { e) Dönüş adası ek levhası }\end{array}$ \\
\hline
\end{tabular}




\begin{tabular}{|l|l|l|l|l|}
\hline & $\begin{array}{l}\text { a) Kasisli köprü yaklaşımı } \\
\text { b) Gevşek malzemeli zemin } \\
\text { c) Kasisli yol } \\
\text { d) Yolda çalışma } \\
\text { e) Tünel yaklaşımı }\end{array}$ & $\begin{array}{l}\text { a) Düşük banket } \\
\text { b) Gevşek malzemeli zemin } \\
\text { c) Gevşek şev } \\
\text { d) Kaygan yol } \\
\text { e) Deniz veya nehir kıyısında } \\
\text { biten yol }\end{array}$ & $\begin{array}{l}\text { a) Olumsuz hava koşulu } \\
\text { b) Gevşek şev } \\
\text { c) Kaygan zemin } \\
\text { d) Kontrolsüz kavşak } \\
\text { e) Gizli buzlanma }\end{array}$ \\
\hline $\begin{array}{l}\text { a) Gizli buzlanma } \\
\text { b) Gevşek malzemeli zemin } \\
\text { c) Kaygan yol } \\
\text { d) Düşük banket } \\
\text { e) Öndeki taşitı geçmek yasaktır }\end{array}$ & $\begin{array}{l}\text { a) Tehlikeli eğim } \\
\text { b) Motorlu taşıt yolu sonu } \\
\text { c) Yolda çalışma } \\
\text { d) Tek yönlü trafik } \\
\text { e) Gevşek malzemeli zemin }\end{array}$ & $\begin{array}{l}\text { Açıklama: Kalın fontta yazılan cevap seçeneği, } \\
\text { "doğru cevap" seçeneğidir. }\end{array}$ \\
\hline
\end{tabular}

Katılımcılardan, anketin Tehlike Uyarı İşaretleri ile ilgili olan kısmını tamamladıktan sonra, Trafik Tanzim İşaretleri ile ilgili olan kısmını cevaplamaları istenmiştir. Anket kapsamında, katılımcılara çoktan seçmeli olarak sorulan Trafik Tanzim İşaretleri Tablo 3' de detaylı olarak yer almaktadır.

Tablo 3. Ankette katılımcılara sorulan trafik tanzim işaretleri

\begin{tabular}{|c|c|c|c|c|c|}
\hline No & $\begin{array}{l}\text { Trafik İşareti } \\
\text { Gösterimi }\end{array}$ & $\begin{array}{l}\text { Kullanıcılara Sunulan } \\
\text { Cevap Seçenekleri }\end{array}$ & No & $\begin{array}{c}\text { Trafik İşareti } \\
\text { Gösterimi }\end{array}$ & $\begin{array}{c}\text { Kullanıcılara Sunulan } \\
\text { Cevap Seçenekleri }\end{array}$ \\
\hline 14 & & $\begin{array}{l}\text { a) Dur } \\
\text { b) Yol ver } \\
\text { c) Taşıı trafiğine kapalı yol } \\
\text { d) Girişi olmayan yol } \\
\text { e) Karşıdan gelene yol ver }\end{array}$ & 15 & & $\begin{array}{l}\text { a) Sağa tehlikeli viraj } \\
\text { b) Sağa tehlikeli devamlı viraj } \\
\text { c) Sağa dönülmez } \\
\text { d) U dönüşü yapılmaz } \\
\text { e) Sağa mecburi dönüş }\end{array}$ \\
\hline 16 & & $\begin{array}{l}\text { a) İleri mecburi yön } \\
\text { b) Park yapılmaz } \\
\text { c) Hız sınırlaması sonu } \\
\text { d) Geçme yasağı sonu } \\
\text { e) Girişi olmayan yol }\end{array}$ & 17 & & $\begin{array}{l}\text { a) Asgari takip mesafesi } \\
\text { b) Azami hız sınırlaması } \\
\text { c) Hız sınırlaması sonu } \\
\text { d) Mecburi asgari hız } \\
\text { e) Mecburi asgari hız sonu }\end{array}$ \\
\hline 18 & & $\begin{array}{l}\text { a) Taşıt trafiğine kapalı yol } \\
\text { b) Taşıt trafiğine açık yol } \\
\text { c) Park yapılmaz } \\
\text { d) Motorlu taşıt yolu sonu } \\
\text { e) Bütün yasaklama ve } \\
\text { kısıtlamaların sonu }\end{array}$ & 19 & & $\begin{array}{l}\text { a) Taşıt trafiğine kapalı yol } \\
\text { b) Park etmek yasaktır } \\
\text { c) Geçme yasağı sonu } \\
\text { d) Bütün yasaklama ve } \\
\text { kısitlamaların sonu } \\
\text { e) Girişi olmayan yol }\end{array}$ \\
\hline 20 & & $\begin{array}{l}\text { a) Genişliği } 3.5 \text { m' den fazla } \\
\text { olan taşı giremez } \\
\text { b) Yüksekliği } 3.5 \text { m' den fazla } \\
\text { olan taşıt giremez } \\
\text { c) Uzunluğu } 3.5 \text { m' den fazla } \\
\text { olan taşıt giremez } \\
\text { d) Yüksekliği } 3.5 \text { m' den az } \\
\text { olan taşıt giremez } \\
\text { e) Asgari takip mesafesi=3.5 m }\end{array}$ & 21 & & $\begin{array}{l}\text { a) Önceliği olan yol } \\
\text { b) İki yönlü yol } \\
\text { c) Şerit düzenleme levhaları } \\
\text { d) Bölünmüş yol öncesi yön } \\
\text { levhası } \\
\text { e) Karşıdan gelene yol ver }\end{array}$ \\
\hline
\end{tabular}


Anketin üçüncü kısmında katılımcıların, Bilgi İşaretleri hakkındaki bilgi ve farkındalık düzeylerinin ölçülmesi amaçlanmıştır. Bu bağlamda, anket kapsamında katılımcılara çoktan seçmeli olarak sorulan Bilgi İşaretleri Tablo 4' de detaylı olarak sunulmaktadır.

Tablo 4. Ankette katılımcılara sorulan bilgi işaretleri

\begin{tabular}{|c|c|c|c|c|c|}
\hline No & $\begin{array}{l}\text { Trafik İşareti } \\
\text { Gösterimi }\end{array}$ & $\begin{array}{l}\text { Kullanıcılara Sunulan } \\
\text { Cevap Seçenekleri }\end{array}$ & No & $\begin{array}{l}\text { Trafik İşareti } \\
\text { Gösterimi }\end{array}$ & $\begin{array}{l}\text { Kullanıcılara Sunulan } \\
\text { Cevap Seçenekleri }\end{array}$ \\
\hline 22 & & $\begin{array}{l}\text { a) Otoyol sonu } \\
\text { b) Anayol sonu } \\
\text { c) Otoyol başlangıcı } \\
\text { d) Anayol girişi } \\
\text { e) Taşıt trafiğine kapalı yol }\end{array}$ & 23 & & $\begin{array}{l}\text { a) Ağır taşıtlar giremez } \\
\text { b) Anayol sonu } \\
\text { c) Girişi olmayan yol kavşağı } \\
\text { d) Otoyol sonu } \\
\text { e) Otoyol başlangıcı }\end{array}$ \\
\hline 24 & & $\begin{array}{l}\text { a) Alt veya üst geçit } \\
\text { b) Yaya geçidi } \\
\text { c) Okul geçidi } \\
\text { d) Yürüyüş yolu } \\
\text { e) Gençlik kamp1 }\end{array}$ & 25 & & $\begin{array}{l}\text { a) İleri çıkmaz yol } \\
\text { b) Taşıt trafiğine kapalı yol } \\
\text { c) Taşıt giremez } \\
\text { d) Girişi olmayan yol kavşağı } \\
\text { e) Kaçış rampası }\end{array}$ \\
\hline
\end{tabular}

Anketin son kısmında ise, iki farklı Durma ve Park etme İşaretine yer verilmiştir ve katılımcılardan bu trafik işaretlerinin ne anlama geldiğini belirtmeleri istenmiştir. Böylece, sıkça karşılaşılan bu iki Durma ve Park etme işaretinin de bilinirlik düzeyleri incelenmiştir. Anket kapsamında, katılımcılara çoktan seçmeli olarak sorulan Durma ve Park etme İşaretleri Tablo 5' de gösterilmektedir.

Tablo 5. Ankette katılımcılara sorulan durma ve park etme işaretleri

\begin{tabular}{|c|c|l|l|l|l|}
\hline No & $\begin{array}{c}\text { Trafik İşareti } \\
\text { Gösterimi }\end{array}$ & $\begin{array}{c}\text { Kullanıcılara Sunulan } \\
\text { Cevap Seçenekleri }\end{array}$ & No & $\begin{array}{l}\text { Trafik İşareti } \\
\text { Gösterimi }\end{array}$ & \multicolumn{1}{|c|}{$\begin{array}{c}\text { Kullanıcılara Sunulan } \\
\text { Cevap Seçenekleri }\end{array}$} \\
\hline 26 & $\begin{array}{l}\text { a) Motorlu taşıt giremez } \\
\text { b) Bütün yasaklama ve } \\
\text { kıstlamaların sonu } \\
\text { c) Duraklamak ve park etmek } \\
\text { yasaktır } \\
\text { d) Duraklamak yasaktır } \\
\text { e) Park etmek yasaktır }\end{array}$ & 27 & $\begin{array}{l}\text { a) Park etmek yasaktır } \\
\text { b) Duraklamak ve Park } \\
\text { etmek yasaktır } \\
\text { c) Duraklamak yasaktır } \\
\text { d) Kontrolsüz kavşak } \\
\text { e) Kontrolsüz demiryolu geçidi }\end{array}$ \\
\hline \multicolumn{2}{|l|}{ Açıklama: Kalın fontta yazılan cevap seçeneği, "doğru cevap" seçeneğidir. } \\
\hline
\end{tabular}

Anket çalışması kapsamında sorulan trafik işaretleri dikkatle incelendiğinde, bu soruların, daha önce yapılan çalışmalarda katılımcılara yöneltilen sorular ile birebir aynı olmadı̆̆ görülebilmektedir. Çalışma kapsamında herhangi bir karşılaştırma yapılması hedeflenmemiştir. Bu yüzden önceki çalışmalarda yer alan sorular doğrudan dikkate alınmamıştır. Bu çalışmada yer alan bazı sorular, önceki çalışmalarda yer alan sorulardan bazıları ile benzerlik gösterse de, benzerlik oranının kayda değer ve yüksek düzeyde olmadığı açıkça görülebilmektedir.

Bu bilgiler ışığında, çalışma kapsamında, temel olarak, önceki çalışmalarda yer alan trafik işaretlerinden ziyade, Denizli'deki sürücülerin günlük hayatta sıkça karşılaştıkları trafik işaretleri kullanılmıştır. Böylece, trafikte bilgi ve farkındalık kavramının Denizli kent merkezi ölçeğinde incelenmesine imkân ve olanak sağlanmıştır.

\section{Bulgular ve Tartışma}

Denizli'deki ehliyet sahibi olan sürücülerin trafik işaretleri hakkındaki bilgi ve farkındalık düzeylerini belirlemek için yapılan anket çalışmas 500 kişi üzerinde uygulanmıştır. Yaş, cinsiyet, meslek ve eğitim durumu ile ilgili sorulara katılımcılar tarafından verilen yanıtlar Şekil 1' de gösterilmektedir. 


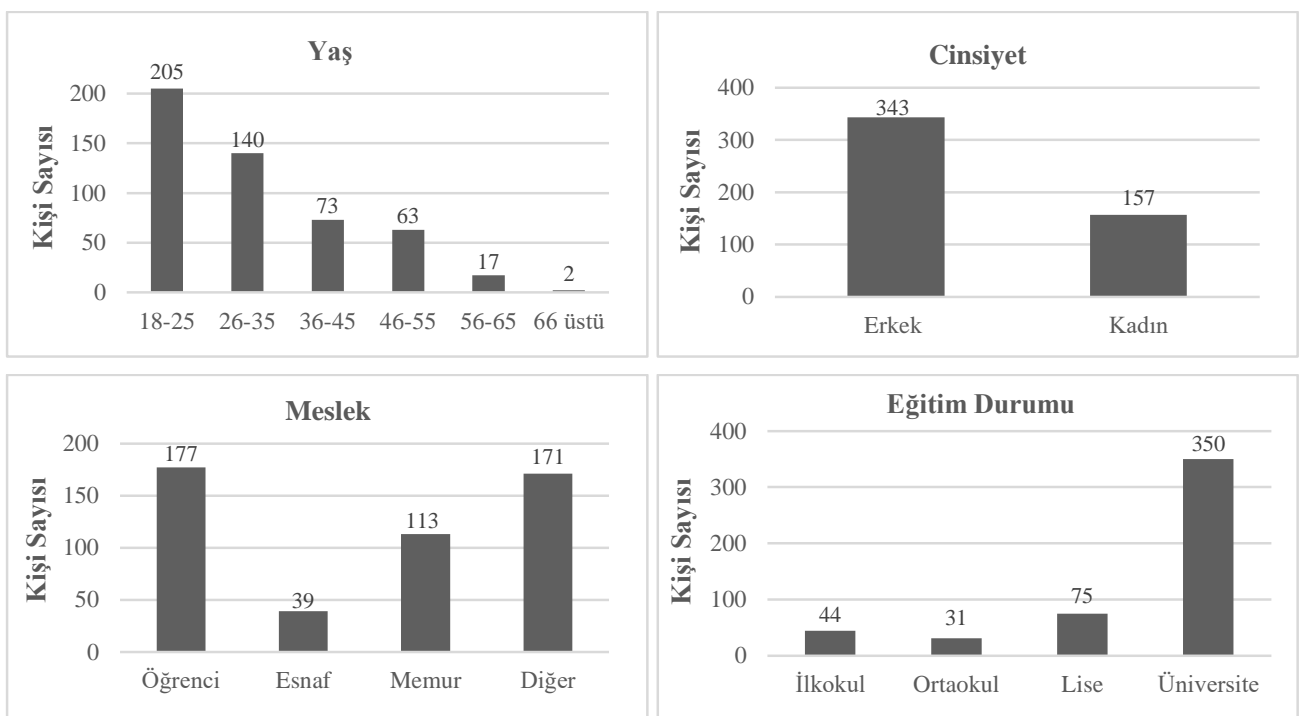

Şekil 1. Ankete katılanların yaş, cinsiyet, meslek ve eğitim durumu dağılımları

Yaş, cinsiyet, meslek ve eğitim durumu ile ilgili analizlerin ardından, trafik işaretleri ile ilgili olan sorulara verilen yanıtlar da MS Excel ortamında ayrı ayrı değerlendirilmiştir. Bu aşamada, katılımcının işaretlemiş olduğu cevap şıkkına "1 puan" verilmiştir. Diğer cevap seçenekleri ise "0 puan" olarak dikkate alınmıştır. Ankete katılan 500 kişinin sorulara vermiş olduğu cevaplara dayalı olarak, her bir soru için bilinirlik yüzdeleri hesaplanmıştır. Bilinirlik yüzdesine göre yapılan değerlendirme kriterleri Tablo 6' da detaylı olarak verilmektedir.

Tablo 6. Trafik işaretlerinin bilinirlik düzeyi değerlendirmesi

\begin{tabular}{|c|c|}
\hline Bilinirlik Yüzdesi (\%) & Bilinirlik Düzeyi \\
\hline $0-20$ arasında & Çok düşük \\
\hline $20-40$ arasında & Düşük \\
\hline $40-60$ arasında & Orta \\
\hline $60-80$ arasında & Yüksek \\
\hline $80-100$ arasında & Çok Yüksek \\
\hline
\end{tabular}

Anket kapsamındaki her bir trafik işareti sorusu için, bilinirlik yüzdeleri ve bilinirlik düzeyleri Tablo 7' de sunulmaktadır.

Tablo 7. Ankette bulunan trafik işaretlerinin bilinirlik yüzdeleri ve bilinirlik düzeyleri

\begin{tabular}{|c|c|c|c|c|c|c|c|c|c|}
\hline : & $\stackrel{\ominus}{\mathbf{Z}}$ & 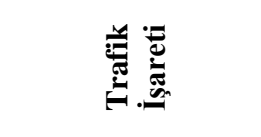 & 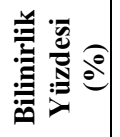 & 戠 & 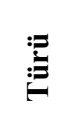 & $\stackrel{\ominus}{\mathbf{z}}$ & 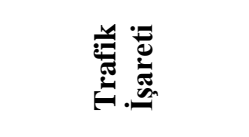 & 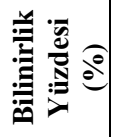 & 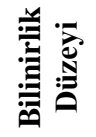 \\
\hline T.U.İ & 1 & Sağa tehlikeli viraj & 63 & Yüksek & T.T.İ & 15 & Sağa dönülmez & 93 & $\begin{array}{l}\text { Çok } \\
\text { yüksek }\end{array}$ \\
\hline T.U.İ & 2 & Kontrolsüz kavşak & 37 & Düşük & T.T.İ & 16 & Girişi olmayan yol & 71 & Yüksek \\
\hline T.U.İ & 3 & $\begin{array}{l}\text { Sola tehlikeli devamlı } \\
\text { virajlar }\end{array}$ & 59 & Orta & T.T.İ & 17 & $\begin{array}{l}\text { Azami hız } \\
\text { sinırlamas1 }\end{array}$ & 82 & $\begin{array}{l}\text { Çok } \\
\text { yüksek }\end{array}$ \\
\hline T.U.İ & 4 & $\begin{array}{l}\text { Ana yol-tali yol } \\
\text { kavşağı }\end{array}$ & 94 & $\begin{array}{l}\text { Çok } \\
\text { Yüksek }\end{array}$ & T.T.İ & 18 & $\begin{array}{l}\text { Taşıt trafiğine kapalı } \\
\text { yol }\end{array}$ & 29 & Düşük \\
\hline T.U.İ & 5 & Tehlikeli eğim (çıkış) & 73 & Yüksek & T.T.İ & 19 & $\begin{array}{l}\text { Bütün yasaklama ve } \\
\text { kısıtlamaların sonu }\end{array}$ & 32 & Düşük \\
\hline T.U.İ & 6 & $\begin{array}{l}\text { Kontrollü demiryolu } \\
\text { geçidi }\end{array}$ & 55 & Orta & T.T.İ & 20 & $\begin{array}{l}\text { Yüksekliği } 3.5 \text { m' } \\
\text { den fazla olan taşıt } \\
\text { giremez }\end{array}$ & 75 & Yüksek \\
\hline
\end{tabular}




\begin{tabular}{|c|c|c|c|c|c|c|c|c|c|}
\hline T.U.İ & 7 & $\begin{array}{l}\text { Her iki taraftan } \\
\text { daralan kaplama }\end{array}$ & 96 & $\begin{array}{l}\text { Çok } \\
\text { yüksek }\end{array}$ & T.T.İ & 21 & $\begin{array}{l}\text { Karşıdan gelene yol } \\
\text { ver }\end{array}$ & 19 & $\begin{array}{l}\text { Çok } \\
\text { düşük }\end{array}$ \\
\hline T.U.İ & 8 & $\begin{array}{l}\text { Tehlikeli viraj yön } \\
\text { levhası }\end{array}$ & 23 & Düşük & B.I & 22 & Anayol sonu & 41 & Orta \\
\hline T.U.İ & 9 & Kasisli yol & 88 & $\begin{array}{l}\text { Çok } \\
\text { yüksek }\end{array}$ & B.í & 23 & Otoyol sonu & 76 & Yüksek \\
\hline T.U.İ & 10 & Düşük Banket & 62 & Yüksek & B.I & 24 & Okul geçidi & 71 & Yüksek \\
\hline T.U.İ & 11 & Kaygan yol & 93 & $\begin{array}{l}\text { Çok } \\
\text { yüksek }\end{array}$ & B.İ & 25 & İleri çıkmaz yol & 87 & $\begin{array}{c}\text { Cok } \\
\text { yüksek }\end{array}$ \\
\hline T.U.İ & 12 & Gizli buzlanma & 70 & Yüksek & D.P.İ & 26 & Park etmek yasaktır & 32 & Düşük \\
\hline T.U.İ & 13 & Yolda çalışma & 99 & $\begin{array}{l}\text { Çok } \\
\text { yüksek }\end{array}$ & D.P.İ & 27 & $\begin{array}{l}\text { Duraklamak ve Park } \\
\text { etmek yasaktır }\end{array}$ & 69 & Yüksek \\
\hline T.T.İ & 14 & Yol ver & 51 & Orta & $\begin{array}{l}\text { T.U.İ: } \\
\text { B.í: } \mathrm{Bi}\end{array}$ & & $\begin{array}{l}\text { r1 İşaretleri / T.T.í: Tr } \\
\text { / D.P.İ: Durma ve Par }\end{array}$ & & $\begin{array}{l}\text { İşaretleri } \\
\text { tleri }\end{array}$ \\
\hline
\end{tabular}

Tablo 7' den görüldüğü üzere, anket kapsamında ele alınan 27 trafik işaretinden 17' si (yaklaşık \%63) çok yüksek veya yüksek düzeyde bilinirliğe sahiptir. Fakat bu işaretlerden 6' s1 (yaklaşık \%23) ise çok düşük veya düşük düzeyde bilinirlik içermektedir. Trafik mühendisliği açısından bakıldığında bu oranın oldukça yüksek olduğu söylenebilir. Trafik işaretlerinin bilinirliğinin şehir içi ve şehirlerarası trafiğin düzenli ve güvenli akışında büyük ve önemli bir role sahip olduğu düşünüldüğünde ise bu yüksek oranın, şehir içi ve şehirlerarası trafiği ciddi derecede olumsuz yönde etkileyebileceği tahmin edilmektedir.

Çalışma kapsamında, trafiğin düzenli ve güvenli akışının sağlanması için yeterli bilinirlik düzeyine sahip olmayan (çok düşük, düşük ve orta) trafik işaretleri ayrı ayrı değerlendirilmiş ve şu bulgulara ulaşı1mıştır:

- Kontrolsüz kavşak (2. soru): Yapılan anket çalışmasında kontrolsüz kavşak işareti için bilinirlik yüzdesi \%37 olarak elde edilmiştir. Bu soruya ait sonuçlar dikkatle incelendiğinde, katılımcıların büyük bir çoğunluğunun bu işaretin anlamını "Taşıt trafiğine kapalı yol" veya "Kontrolsüz demiryolu geçidi” olarak yorumladıkları görülmüştür.

- Sola tehlikeli devamlı virajlar (3. soru): Anket sonuçlarına göre, bu işaret için bilinirlik yüzdesi \%59 olarak elde edilmiştir. Bu soruya yanlış cevap veren katılımcıların yarısının bu işaretin anlamını "Sola tehlikeli viraj" olarak yorumladıkları görülmüştür.

- Kontrollü demiryolu geçidi (6. soru): Anket sonuçlarına göre, bilinirlik yüzdesi $\% 55$ olarak elde edilen trafik işaretidir. Eldeki veriler ışığında, bu soruya yanlış cevap verenlerin çoğunun, bu işaretin anlamını "Kontrolsüz demiryolu geçidi" olarak yorumladıkları görülmüştür.

- Tehlikeli viraj yön levhası (8. soru): Çalışma kapsamında, bilinirlik yüzdesi \%23 olarak elde edilmiştir. Katılımcıların yaklaşı \% \%30' u bu işaretin anlamını "Sola tehlikeli viraj" olarak yorumlarken, \%40' 1 ise "Sola devaml 1 viraj" seçeneğini tercih etmiştir.

- Yol ver (14. soru): Özellikle, sinyal ile denetimin yapılmadığı kavşaklarda karşımıza çıkan "Yol ver" trafik işaretinin bilinirlik yüzdesi \%51 olarak elde edilmiştir. Bu işaretin bilinirlik oranının yarı yarıya olması, sinyal denetimsiz kavşaklardaki trafik kazası görülme sıklığının fazla olmasının nedenini açıkça ortaya koymuştur [16].

- Taşıt trafiğine kapalı yol (18. soru): Bilinirlik yüzdesi \%29 olarak elde edilmiş olan trafik işaretidir. Katılımcıların çoğu bu işaretin anlamını "Taşıt trafiğine açık yol" veya "Bütün yasaklama ve kısıtlamaların sonu" olarak yorumlamışlardır.

- Bütün yasaklamaların ve kısıtlamaların sonu (19. soru): Yoldaki yasaklama ve kisıtlamaların sona erdiğini gösteren bu işaretin bilinirlik yüzdesi \%32 olarak elde edilmiştir. Soruya verilen cevaplar incelendiğinde, diğer cevap seçenekleri arasında dengeli bir dağılımın olduğu görülmektedir. Bu durum, katılımcıların bu trafik işareti hakkında yeterince bilgi sahibi olmadığının bir göstergesidir. 
- Karşıdan gelene yol ver (21. soru): Anket sonuçlarına göre, bu işaretin, bilinirlik yüzdesi en düşük trafik işareti olduğu sonucuna ulaşılmıştır. Katılımcıların \%61' i bu soru için "İki yönlü yol" cevabını vermiştir.

- Anayol sonu (22. soru): Bilinirlik yüzdesi \%41 olarak elde edilmiş olan trafik işaretidir. Bu soruya yanlış cevap veren katılımcıların çoğu bu işaretin anlamını "Otoyol sonu" olarak yorumlamıştır.

- Park etmek yasaktır (26. soru): Özellikle şehir içinde sıkça karşılaşılan bu trafik işaretinin bilinirlik yüzdesi oldukça düşük (\%32) elde edilmiştir. Denizli kent merkezi ölçeğinde düşünüldüğünde, cadde ve sokaklardaki yanlış parklanmanın trafik akışı ile alakalı sorunları da beraberinde getirdiği ortadadır. Bu durumda, sürücülerin trafik işaretleri hakkında daha fazla bilinçlendirilmesi ve farkındalık düzeylerinin arttırılması, kesinlikle sağlanması gereken bir husustur.

Elde edilen sonuçlar dikkatle incelendiğinde, anket kapsamında sorulan ve günlük hayatta sikça karşılaşılan trafik işaretlerinin yaklaşık \% 40 ' 1 nın yeterli düzeyde bilinmediği açıkça görülmektedir. Bu durumun, şehir içinde ve şehirlerarasında trafiğin düzensiz akışına ve trafik kazalarına öncü bir etken olabileceği kesinlikle unutulmamalıdır.

\section{Sonuç ve Öneriler}

Bu çalışmada, Ege Bölgesi' nin en büyük illerinden birisi olan Denizli’ deki sürücülerin günlük hayatta sıkça karşılaşılan trafik işaretleri hakkında, bilgi düzeylerinin yeterli olup olmadığının belirlenmesi amaçlanmıştır. Çalışma kapsamında, öncelikli olarak, 27 adet çoktan seçmeli trafik işareti sorusu hazırlanmış ve hazırlanan sorular anket formuna yerleştirilmiştir. Çalışmanın bir sonraki aşamasında, hazırlanan anket sürücü belgesine sahip olan 500 kişi üzerinde uygulanmıştır. Çalışmanın en son aşamasında ise anket sonuçları MS Excel ortamında değerlendirilmiş ve ankette yer alan her bir trafik işaretinin bilinirlik düzeyleri ayrı ayrı belirlenmiştir. Değerlendirmeler sonucunda elde edilen bulgular genel olarak şu şekilde sıralanabilir:

- Ankette yer alan 27 trafik işaretinden 10' unun, yani yaklaşık \% $\%$ ’ ının, orta, düşük veya çok düşük bilinirlik düzeyine sahip olduğu görülmüştür.

- Bilinirlik yüzdesi \%80' in üzerinde olan trafik işareti sayısı yalnızca 7' dir. Bu durumda, ankette sorulan trafik işaretlerinin yalnızca $\% 25$ ' inin, bilinirlik yüzdesinin $\% 80$ ' den daha fazla olduğu söylenebilir.

• Özellikle, "Kontrolsüz kavşak", "Yol ver" gibi trafik işaretlerinin bilinirlik yüzdelerinin düşük olması, denetimsiz kavşaklarda sıklıkla yaşanan kazaların nedenlerini açıklar nitelikte görülmüştür.

- Genel olarak bakıldığında, yüksek veya çok yüksek bilinirlik düzeyine sahip olan trafik işareti sayısının 17 olduğu görülmektedir. Bu, anketteki trafik işaretlerinin yalnızca \%60' ının yüksek veya çok yüksek bilinirlik düzeyine sahip olduğunu göstermektedir. Bu orandan yola çıkarak, Denizli' de trafik işaret bilinirlik düzeyinin yeterli ve yüksek olmadığı açıkça görülmüştür.

- Çalışmada, "Park etmek yasaktır" işaretinin bilinirlik yüzdesi de oldukça düşük elde edilmiştir. Bu durum, Denizli' deki birçok cadde ve sokakta (özellikle kalabalık yerlerde) yanlış parklanma sonucu görülen düzensiz ve güvensiz trafik akışını da destekler niteliktedir.

Yukarıda sıralanan maddelerden de görüldüğü üzere, trafik işaretlerinin bazılarının bilinirlik düzeyleri yeterli ve uygun değildir. Bu durumun, şehir içi ve şehirlerarasındaki trafik akışını olumsuz yönde etkilememesi için çeşitli uygulamalar gerçekleştirilmelidir. Bu uygulamalara örnek olarak şunlar verilebilir:

- Bireylere, okullarda, küçük yaşlardan itibaren trafik eğitimi verilmeye başlanmalıdır. Eğitimler, gerektiğinde oyunlar, simülasyonlar vb. ile de desteklenmelidir. Bu durumun, trafikte bilgi ve farkındalığı önemli oranda arttırabileceği düşünülmektedir.

- $\mathrm{Bu}$ aşamada, sürücü belgesi alınması sürecinde Sürücü Kurslarına büyük görevler düşmektedir. Kurslardaki trafik eğitimi kalitesi arttırılmalı ve sürücü adayları trafiğe tam anlamılla eksiksiz bir şekilde hazırlanmalıdır. Adaylar için simülasyona dayalı bir eğitimin, trafikte bilgi ve farkındalığı arttırabileceği düşünülmektedir.

- Televizyonlarda, gazetelerde vb. kitle iletişim araçlarında, trafikte bilgi ve farkındalık ile ilgili unsurlara daha fazla yer verildiği takdirde, trafik bilgisi ve farkındalık düzeyinin artırılabileceği düşünülmektedir. 


\section{Teşekkür}

Yazarlar, anket çalışmalarının titizlikle yürütülmesini sağlayan, Pamukkale Üniversitesi Mühendislik Fakültesi İnşaat Mühendisliği Bölümü mezunları Gülşah Çufalı’ ya, Berrin Ötkün’ e, Mehmet Sait Acar' a ve Ayşe Doğan' a teşekkürlerini sunarlar.

\section{Kaynaklar}

1. Çakıcı Z., Murat Y.S. 2016. Sinyalize Dönel Kavşaklar için Hesap Yöntemi Önerisi ve Performans Analizi, İMO Teknik Dergi, 27 (4): 7569-7592.

2. Tortum A., Codur M.Y., Kilinc B. 2012. Modeling Traffic Accidents in Turkey Using Regression Analysis, Iğdır University Journal of the Institute of Science and Technology, 2 (3): 69-78.

3. Temel F., Özcebe H. 2006. Türkiye' de Karayollarında Trafik Kazaları, Sted (Sürekli Tıp Eğitimi Dergisi), 15 (11): 192-198.

4. Brabender B.D., Vereeck L. 2007. Safety Effects of Roundabouts in Flanders: Signal Type, Speed Limits and Vulnerable Road Users, Accident Analysis and Prevention, 39 (3): 591-599.

5. Janpla S., Bumrugrad P., Kularbphettong K. 2015. Developing A Traffic-Sign Knowledge Application on Android System, Procedia - Social and Behavioral Sciences, 191 (2015): 680-685.

6. Yüksel İ. 2002. Sürücü Davranışlarının Stres Oluşturucu Değişkenlere Bağlı Olarak Öngörülmesi, Erciyes Üniversitesi İ.İ.B.F Dergisi, 19: 173-182.

7. http://www.tuik.gov.tr/PreTablo.do?alt_id=1051

8. Al-Madani H., Al-Janahi A.R. 2000. Role of Drivers' Personel Characteristics in Understanding Traffic Sign Symbols, Accident Analysis and Prevention, 34 (2002): 185-196.

9. Shinar D., E Dewar R., Summala H., Zakowska L. 2003. Traffic Sign Symbol Comprehension: A Cross-Cultural Study, Ergonomics, 46 (15): 1549-1565.

10. Ng A.W.Y., Chan A.H.S. 2007. The Guessability of Traffic Signs: Effects of Prospective-User Factors and Sign Design Features, Accident Analysis and Prevention, 39 (2007): 1245-1257.

11. Ng A.W.Y., Chan A.H.S. 2008. The Effects of Driver Factors and Sign Design Features on the Comprehensibility of Traffic Signs, Journal of Safety Research, 39 (2008): 321-328.

12. Tuydes-Yaman H., Kirmizioglu E. 2012. Comprehensibility of Traffic Signs Among Urban Drivers in Turkey, Accident Analysis and Prevention, 45 (2012): 135-141.

13. Özen E., Genç E., Kaya Z. 2014. Trafik Kazalarının Nedenlerine İlişkin Düşünceler ve Trafikte Farkındalık: Uşak İli Örneği, Optimum Ekonomi ve Yönetim Bilimleri Dergisi, 1 (1): 1-14.

14. Ben-Bassat T., Shinar D. 2015. The Effect of Context and Drivers' Age on Highway Traffic Signs Comprehension, Transportation Research Part F: Traffic Psychology and Behaviour, 33 (2015): 117-127.

15. Trifunovic A., Pesic D., Cicevic S., Antic B. 2017. The Importance of Spatial Orientation and Knowledge of Traffic Signs for Children's Traffic Safety, Accident Analysis and Prevention, 102 (2017): 81-92.

16. Murat Y.S., Şekerler A. 2009. Trafik Kaza Verilerinin Kümelenme Analizi Yöntemi ile Modellenmesi, IMOO Teknik Dergi, 20 (3): 4759-4777. 